\title{
ENFERMEDAD RENAL POLIQUISTICA ASOCIADA A LINFOMA EXTRANODAL EN UN CANINO
}

\author{
REN AL POLICYST DISEASE ASSO CIATED TO LYMPHOMA \\ EXTRANODAL IN A CANINE
}

\author{
Diego Echeverry $\mathrm{B}^{1 *}$, Ximena Barbosa $\mathrm{S}^{2}$, Edwin Buriticá $\mathrm{G}^{3}$
}

\begin{abstract}
1Profesor asistente, Universidad del Tolima, Facultad de Medicina Veterinaria y Zootecnia, Clínica de pequeños animales, ${ }^{2} \mathrm{MsC}$. Profesor auxiliar, Universidad del Tolima, Facultad de Medicina Veterinaria y Zootecnia, ${ }^{3}$ Profesor asistente, Universidad del Tolima, Facultad de Medicina Veterinaria y Zootecnia, Clínica de pequeños animales,. Correspondencia: *decheve@ut.edu.co
\end{abstract}

\section{RESUMEN}

O bjetivo: Presentar el caso de un paciente canino, con enfermedad renal poliquística, asociada a linfoma extranodal. Materiales y métodos: Se estudió el caso de un paciente canino de raza Siberian Husky de 7 años de edad, al que se le encontraron múltiples nódulos renales bilaterales, con diagnóstico histopatológico de linfoma extranodal. Resultados: Se expone el caso clínico de un paciente canino de raza Siberian Husky, que es presentado a consulta dermatológica por exhibir lesiones alopécicas multifocales. Una vez realizado el examen físico sistemático se evidenció de manera incidental nefromegalia. Los exámenes paraclínicos e histopatológicos aplicados demostraron la presencia de enfermedad renal poliquística asociada a linfoma extranodal, como consecuencia se presento falla renal crónica. Conclusiones: El linfoma extranodal renal es una entidad patológica de rara presentación, clínicamente cursa con signos muy similares a otras alteraciones tumorales, su diagnóstico suele ser histopatológico.

Palabras clave: linfoma, extranodal, canino, quistes, renal.

\section{ABSTRACT}

0 bjective: To present the case of a canine patient, with renal policyst disease, associated to extranodal lymphoma. Materials and methods: The case of a canine patient Siberian Husky, of 7 years old was studied to which multiple bilateral renal nodules were found, with histopathological diagnostic of extranodal lymphoma. Results: The clinical case of a canine patient of race Siberian Husky is exposed and presented to dermatological consultation to exhibit alopecia multifocal lesions. 0 nce made the systematic physical exam was evidenced nephromegaly in incidental way. The paraclinical and applied histopathological exams demonstrated the presence of renal policyst disease associated to extranodal lymphoma, as consequence renal chronicle alteration was presented. Conclusions: The renal extranodal lymphoma is a pathological entity of strange presentation, clinically frequent with very similar signs to other tumoral alterations, its diagnosis is usually histopathological.

Key words: Lymphoma, extranodal, canine, cysts, renal. 


\section{INTRODUCCIÓN}

El linfoma maligno (linfosarcoma) es una proliferación clonal de linfocitos neoplásicos originada a partir de órganos sólidos, primariamente en los ganglios linfáticos, médula ósea y órganos viscerales. Esto diferencia entre los linfomas y leucemias linfoides, las cuales se originan en la médula ósea $(1,2)$, es el más común de los trastornos linfoproliferativos en caninos $5-10 \%$ de todas las neoplasias caninas (3 - 5).

En caninos, la etiología de los linfomas se considera multifactorial, ya que no se ha identificado un agente etiológico aislado, se cree en una etiología de origen genético, al menos en algunos perros (trisomía del cromosoma 13), además, se han considerado causas ambientales e infecciosas (2).

No obstante, la evidencia de un componente genético, debido a que la neoplasia tiene una evidente prevalencia en ciertas líneas sanguíneas. También existe una predisposición racial distintiva, con algunas razas como Boxer, Basett Hound, Rottweiler, Cocker Spaniel, San Bernardo, Terrier escocés, Terrier de Airdale, Bulldog inglés, Retriver dorado. En felinos el $70 \%$ de los casos está asociado a infección con virus de leucemia felina ( $1-3)$.

En perros y en gatos con linfoma se reconocen cuatro formas anatómicas de presentación, aunque los antecedentes para todas las formas de linfoma maligno se presentan manifestaciones inespecíficas. Entre ellas anorexia, letargia y pérdida ponderal, en la forma multicéntrica la linfadenopatía indolora generalizada es el signo clínico más común distensión abdominal (hepatomegalia, esplenomegalia o ascitis) en algunos pacientes. La forma alimentaria 0 digestiva cursa con signos gastrointestinales co mo vómito, diarrea, anorexia y malestar abdominal, masas palpables. En la forma mediastínica: tos, dificultad deglutoria, anorexia, babeo, respiración laboriosa e intolerancia al ejercicio, tonos cardíacos apagados y efusión pleural $(1,2)$.

En la forma extranodal las manifestaciones dependen del asiento anatómico, en el ocular hay fotofobia y conjuntivitis, uveítis anterior, hemorragias retinianas e hifema. En el sistema nervioso pueden presentarse convulsiones, demencia y parálisis. En piel, lesiones en placas elevadas son manifiestas; en el renal, falla de este órgano y renomegalia; en el corazón intolerancia al ejercicio, arritmias y síncope $(1,2)$.

La incidencia del linfoma canino es de 6-30 por cada 100.000 perros (1), la edad por lo general comprende entre los 5 a 10 años (1-3), la distribución de las diferentes formas a natómicas difiere entre los felinos y caninos. La forma multicéntrica es la más corriente en el perro, representando más del $80 \%$ de todos los linfo mas de esta especie. En los gatos las formas mediastínica y alimentaria son más comunes que la multicéntrica y extranodal $(2,3)$.

El diagnóstico diferencial se hace con enfermedades de tipo infeccioso, neoplásico, inmunomediado e inflamatorio. La evaluación citológica e histológica y la estadificación completa diferenciaran el linfoma de otras patologías (1).

La anemia, linfocitosis, linfopenia, neutrofilia, monocitosis, blastos circulantes y trombocito penia se presentan en muchos animales (1). Aunque la anemia y trombocitopenia son raras (2), la anemia suele ser observada en entidades crónicas (normocítica, normocrómica y no regenerativa) (3).

La elevación de la actividad de la ALT o FA; hipercalcemia se presenta en muchos pacientes, los resultados de orina son generalmente normales, la elevación del nitrógeno ureico y la creatina sérica pueden deberse a la infiltración neoplásica de los riñones.

Las anormalidades hematológicas específicas (monocitosis, reacciones leucemiodes) pueden derivar de la producción local o sistémica de sustancias bioactivas producidas por células tumorales (por Ej., factores de crecimiento hematopoyéticos, interleucinas). Las a normalidades bioquímicas séricas se deben a la producción de sustancias bioactivas por las células cancerosas (paraneoplasia) o insuficiencia orgánica secundaria a la infiltración de la neoplasia. En líneas generales, el hemograma completo y perfil sanguíneo rara vez contribuyen al diagnóstico del linfoma felino y canino $(1,2)$.

Los hallazgos anatomopatológicos incluyen la presencia de masas blancas homogéneas con áreas de necrosis al corte, población monomórfica de células neoplásicas redondas 
discretas que se desprenden y reemplazan al parénquima de los ganglios linfáticos y órganos viscerales o médula ósea $(1,2,4)$ (Figura 1).

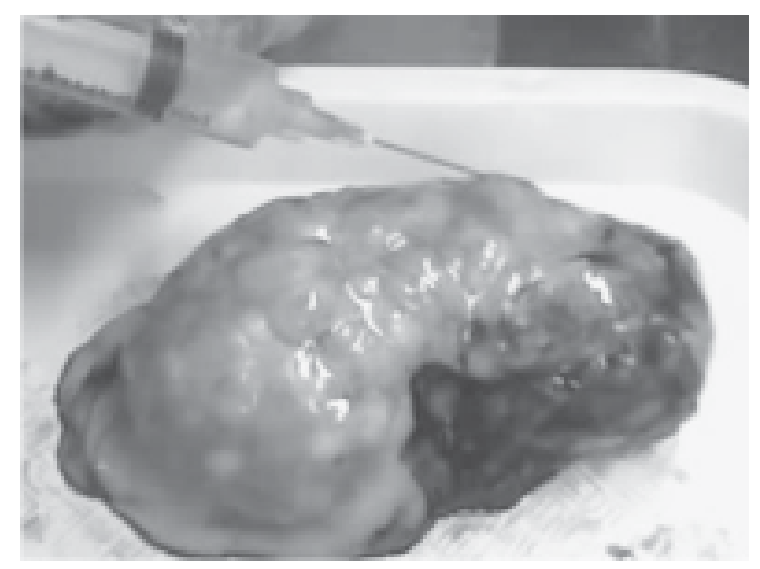

Figura 1. Contenido líquido de los quistes

El tratamiento incluye la administración de quimioterapia, la cual no es curativa pues ocurren recurrencias comúnmente, la tasa de respuesta a la terapia este entre el $70 \%$ y $80 \%$.

El término linfoma extranodal se utiliza para aquellos linfomas cuya localización no esta incluida por las otras agrupaciones anatómicas, por ejemplo renal, nasofaringe, ocular, neural (3).

Los gatos presentan emaciación y palidez (anemia) y se pueden palpar riñones irregulares de gran tamaño (6). En líneas generales, los signos clínicos y hallazgos del examen físico se originan a partir de la compresión 0 desplazamiento de las células parenquimatosas normales del órgano afectado (2).

El linfoma renal es relativamente común en gatos, pero no así en perros (2). Puede presentarse en el $10 \%$ de los linfomas caninos (7).

El diagnóstico se basa en los anamnésicos, las manifestaciones clínicas, el examen físico y exámenes paraclínicos. La mayoría de los perros y gatos con linfoma alimentario, multicéntrico, extranodal y mediastínico, se puede obtener el diagnóstico de manera fácil mediante el uso de biopsia con aguja fina (2). Algunos reportes informaron diagnóstico de linfomas con citología en aproximadamente el $90 \%$ de los perros y el $70-75 \%(1,2)$.

La enfermedad renal poliquística es un desorden en el cual grandes porciones del parénquima renal normalmente diferenciado se ven desplazadas por múltiples quistes con líquido y cubiertos de epitelio $(3,8)$, se desarrollan en los nefrones y conductos colectores preexistentes. De forma invariable se afectan ambos riñones, es posible una naturaleza hereditaria de la enfermedad (1).

Se desconocen los estímulos promotores y secuencias evolutivas, pero serían decisivos los siguientes mecanismos: proliferación tubular sostenida, colecta de líquido del filtrado glomerular y/o excreción transepitelial (8). Como procesos adquiridos se detecta quistes en asociación con displasia, neoplasia, infección y nefritis tubulointersticial (8).

Se puede desarrollar enfermedad quística adquirida en pacientes con cualquier tipo de enfermedad renal crónica o bien como consecuencia de lesiones obstructivas dando lugar a los quistes por retención adquiridos (9).

El diagnóstico diferencial incluye otras enfermedades multiquísticas de los riñones: como enfermedad glomeruloquística del Collie, cistadenocarcinoma renal a sociado con fibrosis nodular del pastor alsaciano, quistes renales asociados con falla renal crónica o displasia renal, causas no quísticas de renomegalia, neoplasia renal, hidronefrosis, pseudoquistes perirrenales, peritonitis infecciosa felina, nefritis micótica o bacteriana (1 - 8).

El líquido de los quistes puede ser transparente, turbio o hemorrágico y el de diferentes quistes de un mismo riñón puede ser variable. El cultivo bacteriano del líquido del quiste es de utilidad para el diagnóstico de la infección concomitante (Figura 1).

La ultrasonografía revela lesiones anecoicas cavitantes caracterizadas por paredes lisas de marginación definida y refuerzo distal que son diagnósticos (Figura 2). Es posible encontrar cavidades quísticas hipo ecoicas en algunos animales con quistes que se han infectado con bacterias, con lo cual se aprovecha para detectar quistes en otros órganos (ej., hígado). Esto es de utilidad para diferenciar entre enfermedad poliquística y procesos multiquísticos adquiridos de los riñones. El aspirado renal con aguja fina puede permitir la diferenciación entre enfermedad quística y otros procesos que generan renomegalia (Figura 1). 


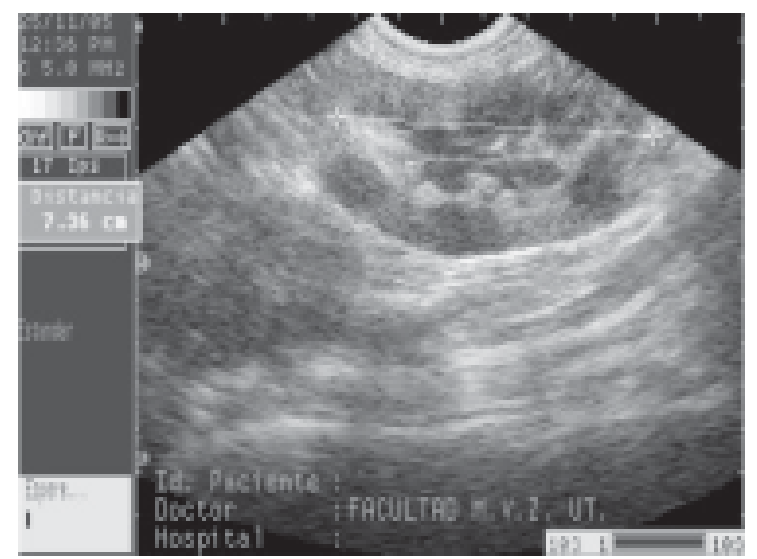

Figura 2. Ecografía renal Evidenciando áreas anecoicas

El tratamiento de los quistes infectados requiere consideraciones especiales. La naturaleza ácida del líquido quístico y su contención con una barrera epitelial podrían inhibir la acción de concentraciones bactericidas de los antibióticos ácidos de empleo corriente dentro del lúmen del quiste como cefalosporinas y penicilinas. Los antibióticos liposolubles alcalinos trimetoprinsulfonamida, enrofloxacina, cloranfenicol, tetraciclinas y clindamicina), que penetran las barreras epiteliales se ionizan y quedan atrapados en la luz de los quistes, recomendados en seres humanos con quistes infectados y deberían ser tenidos en cuenta para los pacientes veterinarios $(1,8)$.

\section{PRESENTACIÓN DEL CASO}

En la clínica de pequeños animales de la facultad de Medicina Veterinaria y Zootecnia de la Universidad del Tolima fue presentado un canino macho de raza Siberian Husky de 7 años de edad, $30.6 \mathrm{Kg}$ de peso y condición corporal 2/5.

El motivo de consulta fue el de presentar lesiones derma tológicas consistentes en pústulas, costras, áreas eritematosas multifocales, lamido de las heridas y vómitos esporádicos. Al examen físico sistemático se evidenciaron riñones agrandados e irregulares, además de esplenomegalia, por lo cual se realizó ecografía abdominal, las constantes fisioló gicas estuvieron dentro de lo normal. Los resultados anormales encontrados en la hematología y bioquímica sanguínea aparecen en la tabla 1 , el examen general de orina en la tabla 2.

Tabla 1. Valores de la bioquímica sérica y hematocrito en el tiempo

\begin{tabular}{|c|c|c|c|}
\hline \multicolumn{4}{|c|}{ HALLAZG OS DE BIOQ UÍMICA EN EL TIEMPO } \\
\hline AN ALITO & VALO R & REFEREN CIA & FECHA \\
\hline$\overline{A L T}$ & $28,5 \mathrm{UI} / \mathrm{L}$ & $10-94 \mathrm{UI} / \mathrm{L}$ & $25 / 11 / 05$ \\
\hline AST & $37,2 \mathrm{UI} / \mathrm{L}$ & $10-62 \mathrm{UI} / \mathrm{L}$ & $25 / 11 / 05$ \\
\hline FA & $149 \mathrm{UI} / \mathrm{L}$ & $0.90 \mathrm{UI} / \mathrm{L}$ & $25 / 11 / 05$ \\
\hline Creatinina & $3,4 \mathrm{mg} / \mathrm{dl}$ & $0,5-1,4 \mathrm{mg} / \mathrm{dl}$ & $25 / 11 / 05$ \\
\hline NUS & $61,3 \mathrm{mg} / \mathrm{dl}$ & $7-32 \mathrm{mg} / \mathrm{dl}$ & $25 / 11 / 05$ \\
\hline Prot. Totales & $11,1 \mathrm{mg} / \mathrm{dl}$ & $7-32 \mathrm{mg} / \mathrm{dl}$ & $25 / 11 / 05$ \\
\hline Albúmina & $1,6 \mathrm{~g} / \mathrm{dl}$ & $3,2-4,7 \mathrm{~g} / \mathrm{dl}$ & $25 / 11 / 05$ \\
\hline G lobulina & $9,5 \mathrm{~g} / \mathrm{dl}$ & $1,5-3,5 \mathrm{~g} / \mathrm{dl}$ & $25 / 11 / 05$ \\
\hline$A / G$ & 0,16 & & $25 / 11 / 05$ \\
\hline NUS & $44,1 \mathrm{mg} / \mathrm{dl}$ & $7-32 \mathrm{mg} / \mathrm{dl}$ & $01 / 12 / 05$ \\
\hline Creatinina & $3,04 \mathrm{mg} / \mathrm{dl}$ & $0,5-1,4 \mathrm{mg} / \mathrm{dl}$ & $01 / 12 / 05$ \\
\hline NUS & $66,14 \mathrm{mg} / \mathrm{dl}$ & $7-32 \mathrm{mg} / \mathrm{dl}$ & $03 / 12 / 05$ \\
\hline Creatinina & $6,4 \mathrm{mg} / \mathrm{dl}$ & $0,5-1,4 \mathrm{mg} / \mathrm{dl}$ & $09 / 12 / 05$ \\
\hline NUS & 72,4 & $7-32 \mathrm{mg} / \mathrm{dl}$ & $09 / 12 / 05$ \\
\hline NUS & 173 & $7-32 \mathrm{mg} / \mathrm{dl}$ & $19 / 12 / 05$ \\
\hline Creatinina & 11,79 & $0,5-1,4 \mathrm{mg} / \mathrm{dl}$ & $19 / 12 / 05$ \\
\hline Hemato crito & $32 \%$ & $37-55 \%$ & $24 / 11 / 05$ \\
\hline Hema to crito & $23,2 \%$ & $37-55 \%$ & $03 / 12 / 05$ \\
\hline Hema to crito & $27,4 \%$ & $37-55 \%$ & $09 / 12 / 05$ \\
\hline
\end{tabular}


Tabla 2. Examen general de orina

\begin{tabular}{ll}
\hline Bilirrubina en orina & + \\
-Proteína en orina & ++ \\
Densidad & 1020 \\
$\mathrm{PH}$ & 6,5 \\
G lóbulos rojos & $2 \times \mathrm{C}$ \\
glóbulos blancos & $1-2 \times \mathrm{C}$ \\
Bacterias & + \\
Cilindros renales & $1-2 \times \mathrm{C}$ \\
\hline
\end{tabular}

En el examen ecográfico se observó la presencia de riñones con numerosos áreas anecógenas compatibles con quistes en el interior del parénquima y áreas hiperecoicas multinodales que podrían ser compatibles con neoplasia (Figuras 3 y 4 ).

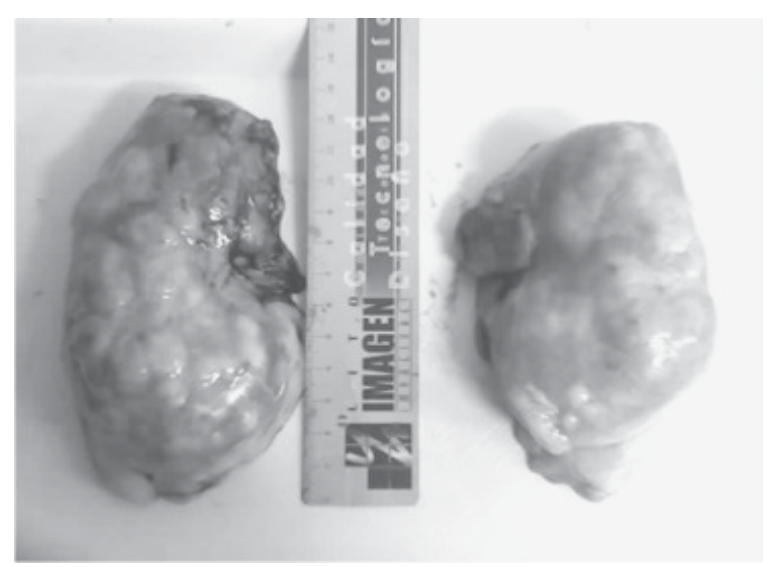

Figura 3. Renomegalia, nódulos y quistes

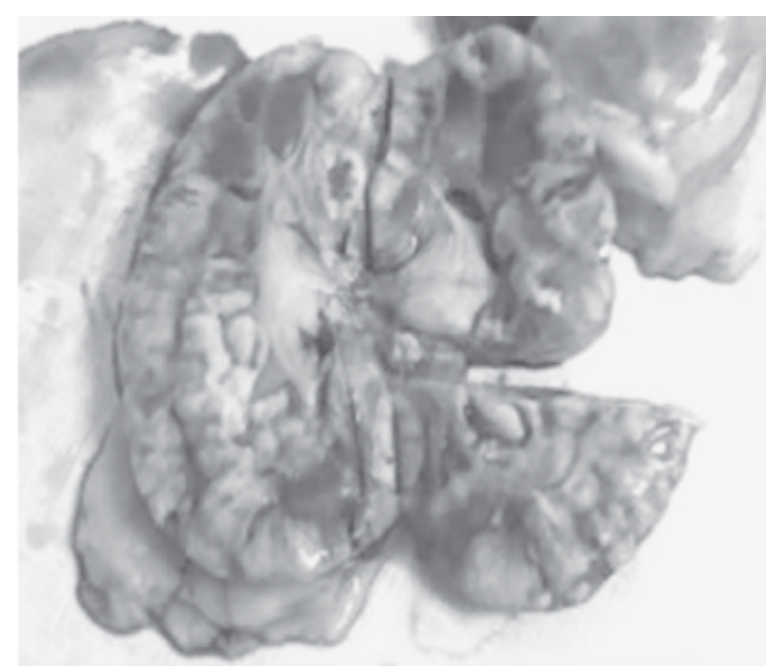

Figura 4. Evidencia de nódulos y quistes
El tratamiento médico se orientó hacia la disminución de la uremia mediante el manejo dietético, para lo cual se utilizó Hills prescription $\mathrm{K} / \mathrm{d}$, al aumento de la diuresis medicándolo con furosemida $3 \mathrm{mg}$ cada 12 horas. Conjuntamente con la terapia de fluidos de mantenimiento (suero fisiológico + dextrosa al $5 \%$ ), con esta terapia se obtuvo la remisión del cuadro clínico consistente en recuperación del a petito, sin embargo, 8 días después retornó el vómito y anorexia.

Se recomendó al propietario la realización de una laparotomía exploratoria y biopsiado, informándose además a cerca de la gravedad del pronóstico ante lo cual insistieron continuar la terapia sin autorizar la laparotomía. Ante la falta de respuesta del paciente al tratamiento evidenciada en la azoemia y uremia se decidió practicar la eutanasia.

A la necroscopia sólo se observaron alteraciones macroscópicas en el sistema renal evidenciadas por la presencia de renomegalia, riñones nodulares e irregulares (Figura 2), mostrando además estructuras poliquísticas con contenido líquido (Figura 3), lesiones presentes en ambos riñones. Histopatológicamente la descripción fue: "se observaron cortes de riñón con infiltración de células inflamatorias de tipo mononuclear: células grandes basofílicas con escaso citoplasma compatibles con linfocitos, presencia de algunos macrófagos y polimorfonucleares neutrofilos. Atrofia de aproximadamente el $60 \%$ de los túbulos contorneados distales, proximales y de corpúsculos renales en la corteza renal, presentación de quistes en el $10 \%$ de la muestra" (Figura 4).

Reemplazo de corpúsculos renales por tejido fibrilar eosinofílico compacto vascularizado y con gran proliferación de fibroblastos, indicando tejido cicatrizal en el $50 \%$ de los cortes. Se observó formación de centros germinales e hiperplasia de células linfocíticas juveniles. Diagnostico histológico: linfoma, proceso inflamatorio de tipo crónico (Figura 5). 


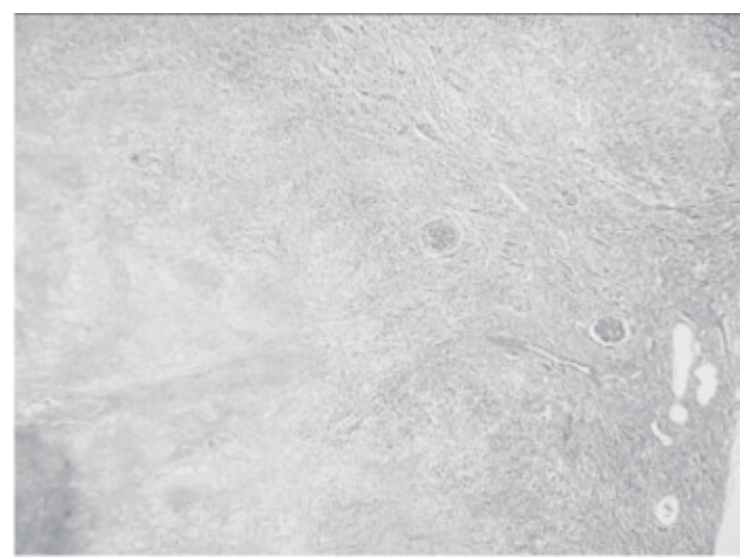

Figura 5. Corte histológico renal mostrando proliferación de células linfoides blásticas

\section{RESULTADOS Y DISCUSIÓN}

Basados en los datos anamnésicos, la exploración física, el resultado de los exámenes paraclínicos e histopatológicos el diagnóstico final de este paciente fue el de linfoma extranodal, enfermedad renal poliquística y falla renal crónica.

El diagnóstico diferencial se hace con enfermedades de tipo infeccioso, neoplásico, inmunomediado e inflamatorio. La evaluación citológica e histológica y la estadificación completa diferenciaran el linfoma de otras patologías (1).

Es importante la difusión de este caso clínico en la literatura médica veterinaria dado a que el linfoma renal es relativamente común en los gatos pero raro en los perros (2); puede presentarse en el $10 \%$ de los linfomas caninos (7).

Los resultados arrojados por la evaluación ecográfica consistentes en alteraciones mixtas de ecogenicidad, la presencia de riñones hiperecogénicos con numerosos quistes anecogénicos en el interior del parénquima, son compatibles con los reportados en la literatura revisada (2) para el linfoma renal y la enfermedad renal poliquística (Figura 4).

En caninos, la etiología de los linfomas se considera multifactorial, ya que no se ha identificado un agente etiológico aislado. Se cree en una etiología de origen genético, al menos en algunos perros (trisomía del cromosoma 13), además se han considerado causas ambientales e infecciosas (2), no se pudo establecer la genealogía del paciente, lo cual pudo haber servido para identificar factores hereditarios y/o genéticos presentes.

La raza Siberian Husky no se reporta como raza predilecta para la presentación de linfoma canino $(1-3)$.

El análisis de los resultados de los exámenes paraclínicos permite concluir que: la anemia presentada por el paciente puede pudo derivar en la falla renal crónica presente en el paciente $(1,2)$. La anemia es una de las anormalidades más comunes que se encuentran asociadas con linfoma, se presenta por arriba de un $38 \%$ de los casos. Ésta generalmente es de tipo normocítica, normocrómica, no regenerativa (anemia crónica) aunque no se ha encontrado una causa clara de la anemia, esta puede ser secundaria a una inflamación crónica asociada a la enfermedad, a un tiempo de vida disminuído de los eritrocitos, a un metabolismo anormal del hierro o bien a una respuesta disminuída de la médula ósea a la eritropoyetina $(9,10)$.

La hiperproteinemia se presenta rara vez en perros y gatos con linfoma. En menos de un $5 \%$ de los casos se puede encontrar una elevación de IgG, IgA o IgM producida por linfocitos malignos tipo B. La alteración de las proteínas séricas puede causar un síndrome de hiperviscosidad, causando diátesis hemorrágica, signos nerviosos, lesiones oculares y lesiones renales (10).

En el paciente no se presentaron cambios en la cuenta leucocitaria y plaquetaria. En líneas generales, el hemograma completo y perfil sanguíneo rara vez contribuyen al diagnóstico del linfoma felino y canino $(1,2)$.

Las anormalidades bioquímicas séricas presentadas en nuestro paciente pueden deberse a la producción de sustancias bioactivas por las células cancerosas (paraneoplasia) evidenciado en la elevación de la FA aunque no puede descartarse la insuficiencia hepática en este paciente pues las enzimas hepáticas no siempre se elevan en presencia de enfermedad hepática, respecto a los valores normales de ALT y AST. La azoemia se originó debido a la insuficiencia orgánica 
secundaria a la infiltración de la neoplasia en el riñón.

La hipoalbuminemia pudo ser debida a la pérdida renal (proteinuria) evidenciada en el paciente, sumada a la hipoalbuminemia generada por la hiperglobulinemia presente en el linfoma y otras enfermedades neoplásicas.

Los hallazgos anatomopatológicos estan de acuerdo con la literatura revisada $(1,2,4)$, incluyendo la presencia de masas blancas homogéneas con áreas de necrosis al corte.

Respecto a la presentación de enfermedad renal poliquística podemos concluir que esta se desarrolló como consecuencia del linfoma. Se puede desarrollar enfermedad quística adquirida en pacientes con cualquier tipo de enfermedad renal crónica o bien como consecuencia de lesiones obstructivas dando lugar a los quistes por retención adquiridos, se reporta que el linfoma y otras tumoraciones predisponen a la presentación de enfermedad renal poliquística (11).

El deterioro progresivo de la función renal manifestado en la elevación casi permanente de los valores de creatinina y NUS, evidencia la magnitud del daño renal así como su evolución desfavorable, que finalmente condujo a la eutanasia del paciente.

Cabe destacar la importancia que tiene un examen semiológico, realizado de manera ordenada, ló gica y completa en el diagnóstico médico, pues en este caso los hallazgos más importantes no tenían su asiento en la piel, lo cual generó el motivo de consulta, gracias a una palpación adecuada se logró identificar la alteración renal. De otro lado, la ecografía fue determinante como método de diagnóstico clínico no invasivo, sin embargo, solo la histopatología permitió llegar a un diagnóstico definitivo.

\section{REFERENCIAS}

1. Tilley PT, Francis KS. La consulta Veterinaria en cinco minutos. Buenos Aires. Editorial Intermedica, 1998; p.820-821.

2. Nelson RW, Couto CG. Medicina interna de animales pequeños. USA. Intermedica. 2005; 2: p.1191-1202

3. Birchard JS. Manual clínico de pequeñas especies. México. Primera edición, Editorial McG raw-Interamericana. 1994; 2: p.230-238.

4. Mucha CJ, Sorribas CE, Consulta rápida en la clínica diaria. Buenos Aires. Editorial Intermedica. 2005; p.649-652

5. Cardoso MJ, Machado LH, Moutinho FQ, Padovani CR. Sinais clinicos do linfoma canino. Arch Vet Sci 2004; 9: p.19-24.

6. Morris J, Dobson J. O ncología en pequeños animales. Buenos Aires. Intermédica. 2002; p.206-207.

7. Ettinger SJ, Feldman EC. Textbook of veterinary internal medicine, diseases of the dog, Philadelphia $4^{\text {th }}$ ed. Saunders Company.1995; p.1936.

8. Taibo RA. Nefrourologia clínica. Buenos Aires. Intermedica. 1999; p.219-228

9. Moreno $A B$, Boiso J, Hervás R, Chacón F. 2005. Enfermedad renal poliquística. $\mathrm{h} \mathrm{t} \mathrm{t} \mathrm{p}:$ / / m e v e p a c I / modules. php? name $=$ News\&file $=$ article $\&$ sid $=361$

10. Álvarez FJ. Curso de oncología en pequeñas especies. Asociaciones de Médicos Veterinarios Especialistas en Pequeñas Especies y Colegios de Médicos Veterinarios Zootecnistas del área Metropolitana de la Ciudad de México. http:// www.a mmvepe.com/oncologia/ cursodeoncologia.pdf 6 de Abril de 2006

11. O sborne C A. Enfermedad renal poliquística. La consulta veterinaria en

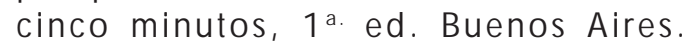
Intermédica Editores. 1998; p.587. 